\section{EXTENDING THE LIFE OF DENTAL HANDPIECES}

Dental handpieces are arguably the hardest working instruments in daily practice. While they're designed to provide years of service, they can only do their job effectively if these valuable instruments are decontaminated and maintained with scrupulous care after every use.

Handpieces are also a centre of focus around the problem of crosscontamination with an emphasis on aerosol reduction and sterilisation processes - crucial issues where NSK is already leading the way.

For example, NSK's Ti-Max Z95L 1:5 speed increasing contra-angle is fitted with the world's first two-way spray technology designed to minimise aerosols. Just a twist of a switch changes the air/water mix to water jet only and the built-in micro filter prevents particles entering the water system.

Ensuring the hidden internal surfaces and hollow channels (lumens) deep within the handpiece chamber is a significant challenge when it comes to effective sterilisation after surgical use. As part of NSK's decontamination range the iMax S S-type autoclave and iClave plus B-type vacuum autoclave have been developed to effectively take handpieces through the sterilisation process.

Utilising a thermally efficient copper chamber that gives faster, more efficient cycles compared to stainless steel counterparts plus enhanced thermodynamic drying, these autoclaves ensure handpieces are better protected from corrosion, discolouration and recontamination, with the added benefit of providing an ongoing reduction in instrument and autoclave maintenance costs.

NSK is world renowned for its innovative development of precisionengineered dental handpieces. Its equally innovative, high-performance decontamination equipment helps practices maintain handpieces in peak condition, whilst also effectively and efficiently reprocessing them for safe and reliable use, time after time.

Find out more about NSK's wide range of decontamination equipment at mynsk.co.uk/decontamination/.

\title{
FUTURE-PROOF YOUR PRACTICE TEAM
}

The recruitment challenges that practices are facing as a result of COVID-19, Brexit and regulatory reforms have led to practice management nationwide being put under a great deal of pressure, particularly with the surge of patients post-lockdown. These unknowns may be out of your control but redirecting your focus to what can be actively managed will enable you to retain and attract valuable team members.

Software of Excellence want to provide you with solutions that will promote a harmonious and happy working environment - introducing a toolkit of Dentist Portal and MyPractice Cloud Pay (MPC Pay) will allow for just this.

Empowering team members with their own data will provide your practice with a degree of transparency that will leave your staff feeling valued throughout their journey with you, without having to lose control of the 'important stuff'. Integrating seamlessly with Dentist Portal, MPC Pay provides greater clarity for associates in terms of their income and performance - allowing them to be better informed over their contribution to the practice and to take ownership of discussions surrounding it. From clear and concise breakdowns of their earnings/deductions to KPI summaries and invoicing, individuals are able to review, forecast and enhance their performance on the go like never before.

Uncovering information in this way not only reveals opportunities for your team members but also for the overall success of your practice. Growing your practice no longer relies solely on the quality of dental care you provide, but stems from the foundations of a great practice team. This is why building strong staff relationships are absolutely crucial, and with the technology now to support this, trust within a team can be built from the very first instance.

The team is the most important asset a dental practice has and as leaders, dentists and managers should strive to show personal commitment to their teams and find new ways to inspire confidence in the future. Empowering, encouraging and listening to your staff will help boost their morale.

Talk to the Software of Excellence team today about how you can drive individual and practice performance with Dentist Portal and MPC Pay - call 01634266800.

For more information visit: www.softwareofexcellence.com.

\section{AWARD-WINNING DISINFECTANTS ON DEMAND}

Dentaqua has been awarded the prestigious Seal award for sustainable product in the dental industry. The SEAL Sustainable Product Award is a global award that honours innovative and impactful products that are 'purpose-built' for a sustainable future. Dentaqua is delighted to be named as a sustainable product winner. It is in recognition of the positive impact that the product has on a dental clinic's carbon footprint.

Dentaqua replaces traditional chemical disinfectants with a device that produces eco-friendly disinfectants on demand. Dentaqua's device produces a dental practice's entire disinfectant needs for use in surface disinfection, hand sanitising, impression disinfection, dental waterline disinfection, and more.

The only inputs to the device are water and a trace amount of salt, the disinfectant produced is non-toxic, yet has a 30 second kill time according to EN 14476. Dentaqua is very proud to be the first dentistry product to win a SEAL Award for sustainability.
Dentaqua is passionate about protecting people from microbial risks. It develops and manufactures patented devices for the in situ production of sustainable, nontoxic disinfectants. By the electrolysis of water and salt, the technology produces all your general disinfectant, environmental decontamination and water-related disinfection needs.

For more information, visit www.dentaqua.com.

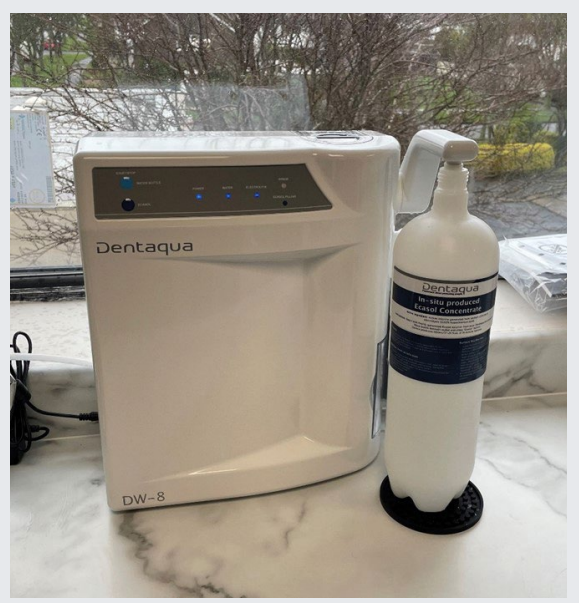

